\title{
Методика оценки удовлетворенности пользователей сайтов судов общей юрисдикции (на примере сайта Фрунзенского районного суда Санкт-Петербурга)
}

\author{
К.С. Кондратенко \\ Санкт-Петербургский государственный университет \\ k. kondratenko@spbu.ru
}

\section{Аннотация}

Статья затрагивает довольно актуальную на сегодняшний день проблему удовлетворенности пользователей сайтов государственных органов РФ, в частности, сайтов судов общей юрисдикции. В качестве примера был выбран сайт Фрунзенского районного суда, поскольку сайты судов являются одними из наиболее востребованных гражданами среди государственных сайтов (сайт именно Фрунзенского районного суда выбран случайно).

Исследование базируется на известных методах проведения подобных исследований юзабилити-тестинга и экспертного опроса. В качестве ключевых аналитических параметров были выбраны общие принципы веб-эргономики, описывающие модель взаимодействия «человек-компьютер» с точки зрения эвристического подхода к программному обеспечению. Также в исследовании производится анализ расхождения ожидания и восприятия пользователей и вычисляется индекс удовлетворенности пользователей (CSI).

Статья может быть полезна разработчикам сайтов, веб-дизайнерам, тестерам, модераторам юзабилити-исследований, специалистам в сферах цифрового публичного управления, юриспруденции, политологии, а также всем интересующимся данной проблематикой.

Ключевые слова: юзабилити, юзабилити-тестинг, юзабилити-тестирование, государственные сайты, сайты органов государственной власти, индекс удовлетворенности пользователей, удовлетворенность пользователей

\begin{abstract}
Библиографическая ссылка: Кондратенко К.С. Методика оценки удовлетворенности пользователей сайтов судов общей юрисдикции (на примере сайта Фрунзенского районного суда Санкт-Петербурга) // Государство и граждане в электронной среде. Выпуск 3 (Труды XXII Международной объединенной научной конференции «Интернет и современное общество», IMS-2019, Санкт-Петербург, 19 - 22 июня 2019 г. Сборник научных трудов). - СПб: Университет ИТМО, 2019. C. 48 - 65. DOI: 10.17586/2541-979X-2019-3-48-65
\end{abstract}

\section{1. Введение}

Концепция государственной информационной политики РФ появилась более 20 лет назад. Проект Концепции разработал коллектив ученых Института системного анализа РАН под руководством проф. Д.С. Черешкина в 1997 г. [1]. Сама Концепция была одобрена на заседании Комитета Государственной Думы по информационной политике и связи 15 октября 1998 г., а также на заседании Постоянной палаты по государственной информационной политике Политического консультативного совета при Президенте Российской Федерации 21 декабря 1998 г. 
Базовыми принципами государственной информационной политики, определенными Концепцией, являются:

- принцип открытости политики;

- принцип равенства интересов;

- принцип системности;

- принцип социальной ориентации;

- принцип государственной поддержки;

- принцип приоритетности права [1].

Одним из основных направлений государственной информационной политики в развитии научно-технического и производственного потенциала информатизации, телекоммуникаций и связи, обозначенных Концепцией, является регулярное проведение оценки состояния подотраслей информационной сферы.

В соответствии с Концепцией государственной информационной политики была разработана Концепция информационной политики судебной системы, принятой постановлением Совета судей Российской Федерации от 16.11.2001 N 60 [2], в которой информационная политика судебной системы понимается как проведение комплекса мероприятий нормативно-правового, организационного, научно-исследовательского, издательского и иного характера, направленных на гармонизацию отношений судебной власти и общества, понимание гражданами сложности проводимой в государстве судебной реформы, пропаганду идей правосудия, а также на объективное освещение деятельности судов в средствах массовой информации [2].

Основной закон, регулирующий информационную деятельность судов РФ, - это Федеральный закон 22.12.2008 N 262-Ф3 «Об обеспечении доступа к информации о деятельности судов в Российской Федерации» [3]. Основные принципы обеспечения доступа к информации о деятельности судов, согласно данному закону: открытость и доступность информации о деятельности судов, за исключением случаев, предусмотренных законодательством Российской Федерации; достоверность информации о деятельности судов и своевременность ее предоставления; свобода поиска, получения, передачи и распространения информации о деятельности судов любым законным способом; соблюдение прав граждан на неприкосновенность частной жизни, личную и семейную тайну, защиту их чести и деловой репутации, права организаций на защиту их деловой репутации; соблюдение прав и законных интересов участников судебного процесса при предоставлении информации о деятельности судов; невмешательство в осуществление правосудия при предоставлении информации о деятельности судов.

На создание единого информационного пространства судебной системы в 2004-2006 гг. было потрачено 1,5 млрд рублей, еще 2 млрд рублей было запланировано на внедрение и развитие целевой федеральной программы «Развитие судебной системы» [4]. Тендер на создание государственной автоматизированной системы (ГАС) «Правосудие» выиграло головное предприятие Мининформсвязи ФГУП «НИИ “Восход”», которое также победило в конкурсе на право заключения госконтракта стартовой стоимостью 672,6 млн рублей для ввода ГАС «Правосудие» в эксплуатацию в 2007 году. Иными словами, государственные расходы на реализацию информационной политики судебной системы составляли около 500 млн. рублей ежегодно. Сложно сказать, какой объем этих средств был потрачен на создание сайтов. Но если взять за основу стартовую стоимость госконтракта 2007 года и разделить его на количество судов, составлявших 2712 судов на 2007 год, то получится цифра в 248 тыс. рублей на создание одного сайта, что даже по меркам 2019 года представляется совсем не малыми средствами.

Бесшабашнов С.В. и Денисов А.А. в статье 2006 г. «Сайт от идеи до реализации» указывают следующие примерные суммы на создание сайта, дифференцируя ценовые показатели в зависимости от уровня квалификации разработчика:

1. Демпинговые цены: от 300 до 1500 EUR («Студенты» - 84\% рынка);

2. Низкие и средние цены: от 1500 до 3000 EUR («Претенденты» - 10\% рынка); 
3. Средние цены и выше средних: от 3000 до 10000 EUR («Профессионалы» - 5\% рынка);

4. Высокие: от 10000 до 40000 EUR («Элита» - 1\% рынка) [5].

Если учесть, что курс евро в 2007 году составлял около 35 руб. за евро, то получится сумма, составляющая примерно 7000 евро, т.е. необходимая на расходы услуг разработчиков-профессионалов.

В то же время сайты судов общей юрисдикции далеки до совершенства: их сложно назвать удобными, интуитивно понятными, создающими пространство пользовательского комфорта. Чтобы развеять эти сомнения, достаточно обратиться к научной литературе по веб-эргономике и юзабилити сайтов, описывающей принципы и методологию проведения исследования сайтов.

\section{2. Методы}

Общетеоретической основой исследования послужили работы Р.В. Проктора, Ву Л. Кимфуна, А. Сеффа, Я. Гулликсена, М. К. Десмариса. Р.В. Проктор и Ву Л. Кимфун достаточно лаконично формулируют принципы веб-эргономики: ориентированный на пользователя дизайн (user-centered design), включающий в себя полезность (used), пригодность (useable) и регулярную используемость (used) [6, p. 29]. Иными словами, центр взаимодействия «человек-компьютер» (Human-Computer Interaction) определяется учеными довольно однозначно - это человек, пользователь. Эту мысль развертывают, в частности, А. Сеффа, Я. Гулликсен и М.К. Десмарис, предложивших следующий набор принципов дизайна системы, ориентированного на пользователя (User-centered system design): ориентация на пользователя; активное участие пользователей; эволюционная разработка систем; простота дизайна; прототипирование; контекстуальное использование; конкретные и осознанные действия по дизайну; профессионализм; юзабилити; целостность дизайна; настройка процессов; ориентация на пользователя всей команды проекта [7, p. 26-29].

Темы взаимодействия «человек-компьютер» и юзабилити сайтов достаточно подробно проработаны в научной литературе, поэтому, чтобы не расширять рамки исследования, сошлюсь на три основополагающих труда, описывающих принципы и методологию юзабилити - это работы Я. Нильсена «Юзабилити инжиниринг» (1993), М.А. Блайта, К. Овербика, Э.Ф. Монка и П.К. Райта «Фанология: от юзабилити к удовольствию» (2004) и С. Круга «Не заставляйте меня думать: веб-юзабилити и здравый смысл» (2005).

Еще в 1993 году Якоб Нильсен сформулировал основные эвристические принципы программного обеспечения, которые служат маяками для проведения юзабилити-тестинга, а именно:

- диалоги (имеются в виду, диалог «человек-система») не должны содержать никакой неактуальной или редко используемой информации;

- диалоги должны быть выражены в тексте и понятиях, знакомых пользователям;

- пользователям не нужно запоминать информацию, которую они используют при переходах из одной части диалога в другую;

- пользователи не должны задаваться вопросом, означают ли разные слова, ситуации или действия одно и то же;

- пользователи всегда должны быть информированы о том, что происходит в системе;

- система должна помогать пользователям выходить из любой нежелательной ситуации;

- ярлыки должны ускорять выполнение задач;

- сообщения должны на простом языке излагать проблему и предлагать решение;

- по возможности, системы должны предотвращать возникновение проблем;

- информация должна легко извлекаться и содержать перечень необходимых шагов для выполнения задач [8, p. 115-163].

Стив Круг еще больше упростил принципы работы сайта и методологию юзабилити, поместив базовое правило в название своей работы - «Не заставляйте меня думать» [9]. Речь 
здесь идет не о том, чтобы пользователь не думал вообще, а о том, чтобы он не ломал голову над устройством сайта. Пользователи не должны специально обучаться работе с сайтом, а сама система должна водить за руку пользователей и помогать как можно быстрее достигать поставленных целей. Такой подход ставит довольно сложную задачу перед разработчиками - усложнение мыслительных процессов пользователя о своих целях за счет упрощения представления информации. Мыслительные процессы пользователя должны, в свою очередь, менять саму систему; смысл в данном случае намного важнее информации $[10, \mathrm{p}$. 26-27].

Данному исследованию также оказались весьма полезными работы Дж.С. Думаса и Б.Л. Лоринг «Модерация юзабилити-тестов. Принципы и практика взаимодействия» [11] и Л. Вроблевски «Просмотр сайта: визуальный подход к веб-юзабилити» [12], которые помогли автору скорректировать стратегию проведения юзабилити-тестинга, а также работа С.Дж. Койани, Р.В. Бэйли и Дж.Р. Нэлла «Научный подход к веб-дизайну и рекомендации для юзабилити» [13], в которой легким и доступным языком описаны принципы дизайна исследований сайтов.

Расчет основных показателей в исследовании основывался на работах М. Фишбейна, А. Айзена [14], А.П. Парасурамана, В.А. Зейтамл, Л.Л. Берри $[15,16]$. Индекс удовлетворенности пользователей (CSI) рассчитывался по известной формуле ФишбейнаАйзена. Несмотря на его простоту и довольно общий характер, он позволяет определить уровень сопротивления пользователей системе и дать оценку их удовлетворенности от работы с сайтом. Методика SERVQUAL, описанная в работах А.П. Парасурамана, В.А. Зейтамл и Л.Л. Берри, в целях данного исследования была существенно упрощена измерялись только базовые величины, а не их составляющие. По этой причине вычисление коэффициента альфа Кронбаха представляется затруднительным, поэтому для индексного измерения величины расхождения ожидания и восприятия пользователей использовалась методика расчета относительной депривации (RD) T.P. Гарра [17, с. 108].

Основные принципы электронного правосудия, описанные в диссертационных исследованиях А.В. Аносова, Е.И. Кокотовой и М.В. Чижова $[18,19,20]$, позволили автору конкретизировать принципы разработки сайтов судов и их правовое обеспечение.

Соответствию сайтов судов общей юрисдикции российскому законодательству, в первую очередь, Федеральному закону 22.12.2008 N 262-Ф3 «Об обеспечении доступа к информации о деятельности судов в Российской Федерации», посвящено достаточное количество исследований. Существенный вклад в разработку и осуществление мониторинга открытости сайтов органов государственной власти внесли эксперты Института развития свободы информации И.Ю. Павлов, Е.Г. Голубева, В.О. Голубев [21]. Сегодня мониторинг открытости сайтов судов общей юрисдикции осуществляет проект «Инфометр» [22]. Согласно рейтингу открытости сайтов районных судов Российской Федерации, степень открытости сайта Фрунзенского районного суда Санкт-Петербурга на 2017 г. составляет $0,000 \%[23]$.

Скудность литературы о степени удовлетворенности пользователей российских государственных сайтов, выявленной с помощью юзабилити или индекса удовлетворенности пользователей (CSI) обосновывает научную значимость данного исследования. Автор смог выделить всего лишь несколько работ, посвященных данной теме - это статьи «Анализ системы информационного управления в социально-экономической сфере муниципального образования г. Каменск-Уральский» М.В. Завескина [24], посвященная рейтинговой оценке государственных сайтов, «Специфика создания сайта для органов государственной власти» И.О. Страшко [25], в которой описываются основные принципы разработки государственных сайтов, и работа «Сайты государственных организаций: оценка степени соответствия требованиям закона и нуждам пользователей» Г.А. Меньшиковой и С.В. Евстратчик [26], наиболее приближенная к целям данного исследования. В указанной статье проводится анализ девяти кейсов на предмет соответствия законодательству и эргономичности. Статья отличается лаконичностью и 
емкостью, но в то же время не представляет данных о ходе самого исследования, освещая лишь его результаты. Кроме того, вызывает методологическое сомнение факт обращения к студентам как к экспертам-тестировщикам. В методологическом плане, надо полагать, более уместно обращаться к профессионалам для контроля данных, полученных от непрофессионалов.

Таким образом, для достижения поставленной цели, а именно проведения комплексной оценки удовлетворенности пользователей государственных сайтов, наиболее подходящей представляется следующая методологическая схема:

- юзабилити-тестинг рядовых пользователей;

- выявление количественных характеристик (депривационные показатели и индекс удовлетворенности пользователей);

- контрольный опрос экспертов;

- контроль количественных характеристик.

\section{3. Результаты}

\section{1. Этапы исследования и выбор респондентов}

Исследование было проведено в два этапа: фокус-группа и опрос экспертов. Отбор участников фокус-группы производился на основе следующих критериев:

- уверенный уровень владения ПК;

- высокий уровень навыков работы с сетью Интернет;

- наличие достаточно высокого уровня знаний о деятельности органов государственной власти вообще и судебной власти в частности;

- отсутствие контактов с тестируемым сайтом до начала проведения исследования.

Всем критериям в ходе сбора заявок на участие в работе фокус-группы наилучшим образом соответствовали студенты направления подготовки «Конфликтология» СанктПетербургского государственного института психологии и социальной работы, любезно согласившиеся на участие в данном исследовании. Наш выбор пал именно на данную группу по следующим причинам:

- молодежь активно использует Интернет в повседневной деятельности;

- студенты 4 курса уже освоили дисциплины, связанные с государством и правом;

- студенты-конфликтологи осваивают навыки работы медиаторов и знакомы с судебной системой;

- студенты 4 курса, обучаясь в Санкт-Петербургском государственном институте психологии и социальной работы, в большей степени осваивают психологические дисциплины и в меньшей - правовые;

- наконец, студенты-гуманитарии в большей степени способны оценить сайт не с точки зрения технической проработанности, сколько с позиции эстетики, внешнего вида, комфорта.

Группа, состоящая из 23-х человек, работала на персональных компьютерах и смартфонах (для оценки преимуществ и недостатков мобильной версии сайта).

\section{2. Ход исследования}

Оценке подлежал сайт Фрунзенского районного суда г. Санкт-Петербурга. Порядок выбора сайта для проведения исследования - случайный.

Bonрос: Какими правовыми знаниями Вы обладаете? Знакомы ли Вы с судебной системой? Какие юридические курсы Вам были прочитаны?

Ответ 1: «Правоведение», «Документоведение», «Юридическая конфликтология», как устроены суды и как они функционируют пройдено».

Ответ 2: «Технологии переговорных процессов», «Медиация» - курсы, достаточно близкие к общеправовым». 
Пользователи подтвердили информацию о знакомстве с принципами деятельности органов власти и основами права.

Bonpoc: Что Вы думаете о российской судебной системе?

Ответ 1: «Коррупция».

Ответ 2: «Мое отношение сомнительное, 50 на 50. Где-то, когда-то это работает по справедливости, когда-то это не работает вообще, поэтому 50 на 50».

В данных высказываниях пользователей проявилась общероссийская тенденция недоверия судебной системе. Согласно результатам опроса, проведенного «Независимым исследовательским центром» в 2018 году, половина опрошенных россиян $(50 \%)$ в разной степени не доверяют российской судебной системе в целом, а среди причин недоверия людей к российским судам лидирует коррупция (44,6\%) [27].

Далее пользователям было предложено оценить ожидания от работы с сайтом по 10балльной шкале (до начала работы с сайтом непосредственно) по следующим критериям:

- удобство сайта;

- полезность сайта;

- простота и понятность интерфейса;

- приятность и комфорт от работы с сайтом.

Результаты будут представлены в части работы, касающейся расчета индекса удовлетворенности пользователей (CSI).

Вопрос: Посмотрите теперь на главную страницу сайта. На что Вы обратили внимание в первую очередь, во вторую и т.д.? (здесь и далее будут приводиться оригинальные ответы)

Ответ 1: «Сначала был заметен жирный шрифт и герб».

Ответ 2: «В первую очередь мне бросилось в глаза расписание работы суда, приемной».

Ответ 3: «В первую очередь бросилось в глаза большое и страшное объявление посередине страницы».

Ответ 4: «Сначала текст на белом фоне в центре, дальше - выделенная синим цветом строка в меню («Подача процессуальных документов в электронном виде» - прим. К.К.), дальше - «Версия для слабовидящих», потом - герб и название».

Ответ 5: «Первое, что бросилось в глаза - это красный шрифт на черном фоне (вероятно, «Порядок подачи в федеральные суды общей юрисдикции документов в электронном виде, в том числе в форме электронного документа» - К.К.), второе - выделенное синим цветом (вероятно, кнопка «Подача процессуальных документов в электронном виде» - К.К.), третье - это герб и название.

Главная страница сайта Фрунзенского районного суда представлена на рис. 1.

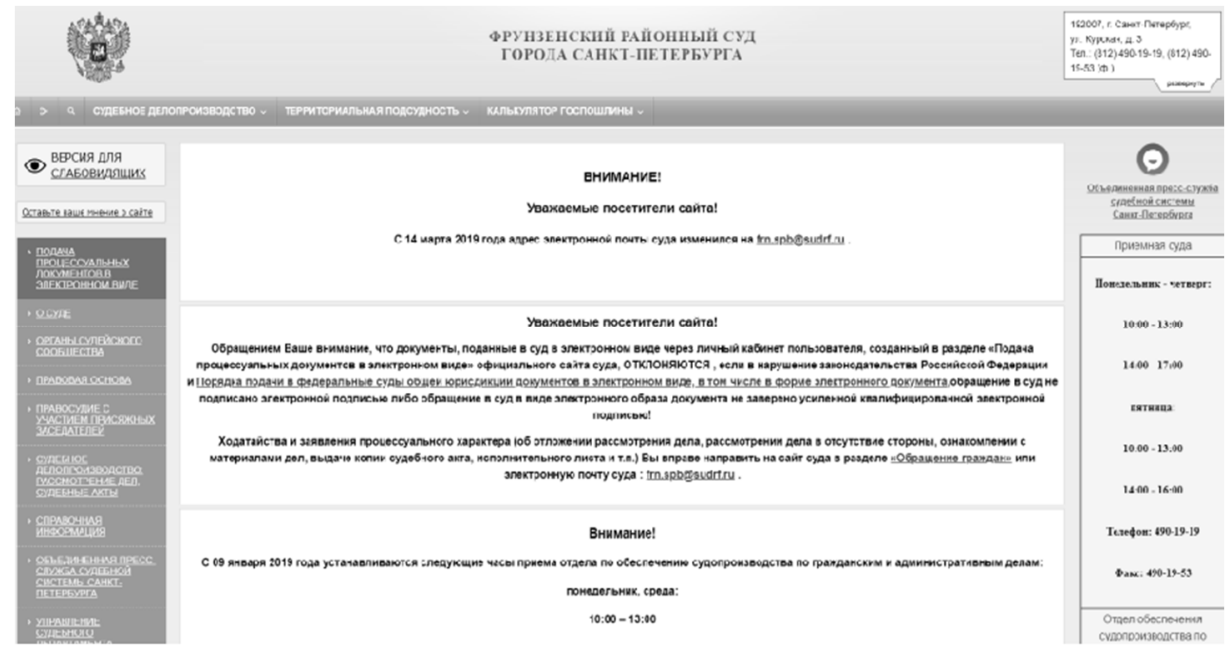

Рис. 1. Главная страница сайта Фрунзенского районного суда г. Санкт-Петербурга 
Большинство пользователей отметили, что первым бросается в глаза заголовок и красный цвет подчеркнутого текста объявления, которое пугает пользователей, первый раз посетивших сайт. Вероятно, объявление лучше было бы убрать в соответствующий раздел, например, в раздел «Подача процессуальных документов в электронном виде». К тому же объявление начинается с обращения к посетителям сайта, за которым следует текст о том, как посетители должны себя вести.

Bonрос: Оцените цветовую гамму сайта. Ваши впечатления?

Oтвет 1: «Цвет выглядит достойно, но не очень презентабельно».

Ответ 2: «Цветовая гамма отталкивающая».

Ответ 3: «Довольно приятная цветовая гамма, ничего лишнего».

Oтвет 4: «Приятный цвет, нейтральный, не вызывает какого-то негатива, вполне комфортный для глаз».

Ответ 5: «Цветов очень много, они диссонируют друг с другом. Основной цвет довольно блеклый, близок к белому, бронзовому. Не самый приятный цвет».

Справедливости ради отметим, что из 23-х студентов лишь двое высказались положительно о цветовой гамме сайта суда и двое - нейтрально.

Bопрос: Оцените удобство левой боковой панели. Все ли Вам понятно?

Oтвет 1: «Примерно все понятно, по названиям ясно, какое содержание там можно найти, формирует ожидания, соответствующие названиям».

Oтвет 2: «Чтобы разобраться во всем этом, нужно иметь понятие во всем этом, а я ничего не знаю, ничего не понимаю».

Oтвет 3: «В принципе все понятно на боковой панели, но непонятно, зачем так много. Долго смотреть на все это и искать что-то нужное».

Ответ 4: «Цвета сливаются - шрифт и фон. Нечитабельно».

Ответ 5: «Сложно читаемый белый цвет на светлом фоне, к тому же еще и подчеркнутый. Плохо читаемо. При этом мне сложно будет найти то, что меня интересует, потому что большинство из этих разделов для меня непонятны и что там находится внутри мне тоже непонятно. Т.е. обычная справочная информация - там понятно, что там можно найти, а что касается управления судебным департаментом, например, мне непонятно».

Oтвет 6: «Все понятно, но цвет текста на фоновом цвете воспринимается не очень четко».

Ответ 7: «Подчёркивание текста раздражает».

В этих ответах обнаруживается две негативные оценки - верстки и содержания. Белый шрифт на бежевом фоне пользователи оценили негативно. Вероятно, разработчикам следовало бы обратить на это внимание. Некоторые понятия пользователям были незнакомы и потому они высказали опасения, что из-за незнания терминологии потратят больше времени на поиск нужной информации. Это говорит не столько о некомпетентности пользователей, сколько о ненужных им временных затратах.

Bonрос: Видите ли Вы кнопку «Назад», «Вперед», «Повторить ввод» и т.д.?

Ответ 1: «Кнопки «Назад», «Вперед», «Пропустить», «Ввод» отсутствуют».

Ответ 2: «Кнопок возврата не видно, не обозначается цветом или иными выделителями, в каком именно разделе находишься».

Ответ 3: «Вернуться на домашнюю страницу нельзя».

Серьезные замечания в сторону разработчиков. Система слабо помогает, если помогает вообще, ориентироваться на сайте и исправлять ошибки ввода данных.

Bonpoc: Оцените шрифт и начертание букв. Пришлось ли Вам присматриваться к буквам? Удобен ли для чтения текст?

Oтвет 1: «Неудобный разный маленький шрифт, однако неплохо, что выделены красным важные слова».

Oтвет 2: «Сам шрифт удобен и его хорошо видно, все портит цветовая гамма и подчеркивание». 
Ответ 3: «Шрифт боковой левой панели нравится, читается легко. Большой центральный текст оставляет желать лучшего».

Oтвет 4: «Шрифт в принципе удобен, довольно крупный, хотя он разный на разных вкладках, однако, поскольку не совсем цвета контрастные, приходится вглядываться и внимательно пытаться читать, сосредотачиваться. А так шрифт понятен сам по себе».

Ответ 5: «Шрифты различаются, нет единого. На левой панели с разделами имеются подчеркивания, что усложняет понимание».

Ответ 6: «Шрифт боковой панели неудобен. Буквы очень тоненькие, еще этот фон ужасный. Боковая панель плохо читается. Верхняя горизонтальная - да, конечно, шрифт уже пожирнее, но все равно белые буквы на светло-серо-коричневом плохо читаются. В принципе, когда открывается информация конкретно из какого-то раздела, там обычный шрифт, который хорошо читается, но конкретно визуально очень сложно найти, то, что нужно. Это затруднительно».

Oтвет 7: «Шрифт в целом в принципе подходит, только не нравится, как белым по этому мрачному фону написано в левом блоке. Также не нравится подчеркивание и выделение красным, можно было выделить Caps Lock'oм».

Ответ 8: «В версии для слабовидящих большой шрифт и изначально его можно сделать еще больше, но, правда, не совсем понятно становится, куда щелкать и как разобраться в структуре сайта, однако зато все читабельно, черным по белому написано».

Oтвет 9: «В мобильной версии сайт выглядит лучше. Нет подчеркиваний».

В целом пользователи отметили приемлемость шрифта основного текста в центре страницы и неприемлемость шрифта левой боковой панели. Вопрос был задан совсем не случайно: дизайн и верстка - первое, с чем имеют дело пользователи, впервые посетившие страницу. Первые впечатления от работы с сайтом накладывают отпечаток на весь процесс работы.

Далее пользователям было предложено выполнить задание. Студенты-конфликтологи 4 курса теоретически могут проходить производственную практику в суде, присутствуя на рассмотрении конкретных конфликтных ситуаций и анализируя ход конфликта и его разрешение. Задание заключалось в том, чтобы студенты нашли контактные данные, попробовали написать электронное обращение, выбрать интересующее их дело и т.д.

Bonрос: Попробуйте понять, к кому и каким образом обратиться с вопросом устройства на практику.

Ответ 1: «Есть контактная информация, благодаря ей можно обратиться и уточнить все, что нужно. Это заняло у меня минуты три».

Ответ 2: «Сверху справа сразу видно адрес и телефон приемной, сразу понятно, куда и кому звонить, потому что обычно на сайтах отдельно есть вкладка «Контакты» или чтонибудь в этом роде и приходится там где-то искать, а тут все видно и сразу бросается в глаза справа сверху отдельной вкладкой».

Ответ 3: «Видна сразу же панелька с адресом и 2 номерами телефонов, но не понятно, для чего он».

Ответ 4: «Непонятно, зачем телефоны и по каким вопросам звонить».

В целом, все студенты справились с этим заданием. Телефон приемной находится на главной странице сайта.

Bonpoc: Допустим, Вы позвонили по телефону несколько раз и Вам не ответили. Может, попробовать написать электронное обращение? Как написать электронное обращение с помощью этого сайта? И возможно ли это?

Oтвет 1: «Тут вообще нигде нет электронного адреса, и, зная такие сайты и такие структуры, мне кажется, что они будут очень долго отвечать и легче позвонить».

Oтвет 2: «На сайте не указан адрес электронной почты, т.е. эта информация не доступна в тех разделах сайта, где указан номер телефона».

Oтвет 3: «Да, понятно все. «Подача процессуальных документов в электронном виде» - сразу самая первая графа в левой колонке. Переходя на нее, видишь довольно приятный 
интерфейс, намного приятней, чем на главной странице. Там есть кнопка «Создать новое обращение», все ясно, есть кнопка «Обратиться в техническую поддержку», чтобы тебе помогли. Вполне можно сориентироваться».

Ответ 4: «Лично я вообще не вижу здесь почты, адрес и телефон есть, почты нет, значит, нужно копаться, искать ее. Опять же даже если ее и найти каким-то случайным образом: чья эта почта, к кому она, по каким вопросам туда обращаться - вообще ничего непонятно».

Студенты искали на сайте эту информацию от 30 секунд до 2-х минут. Это катастрофически много для поиска информации, которая должна быть обнаруживаемой без труда и временных затрат. Даже по истечении 2-х минут модератору пришлось объяснять большинству присутствующих, где находится окошко «Обращение граждан». Второе серьезное замечание в адрес разработчиков.

Bonpoc: Допустим, Вы устроились на практику. В ходе прохождения практики Вы захотели присутствовать на конкретном судебном заседании. На каком именно? Найдите интересующее Вас дело на сайте суда, которое пройдет в ближайшее время (24.12-29.12). Опишите Ваши действия.

Oтвет 1: «Насколько я знаю, на сайтах судов есть каталог, где вводишь либо номер дела, либо дату, и можно посмотреть, какие суды будут. Но здесь я не вижу такого».

Ответ 2: «Сверху есть вкладка «Судебное делопроизводство», она самая первая. Переходя по ней, я вижу расписание, список дел, назначенных к слушанию на 24.12.2018 г., там номер дела, время, место, основная информация по делу, а также указан судья. По категории можно понять, на что бы я хотела сходить, в какое время и пр. На этой неделе 24 числа я бы хотела попасть на судебное заседание о защите прав потребителей, потому что не так давно мои права как потребителя были нарушены, я бы послушала. Это заняло у меня минуту».

Ответ 3: «На этой неделе я бы хотела посетить заседание 24 декабря, которое будет проходить в 12.20, о возмещении ущерба от ДТП, кроме увечий и смерти кормильца».

Ответ 4: «Нужная информация находится в самом низу сайта, т.е. чтобы ее найти, надо пролистать весь сайт до конца, чтобы понять, что нужно. При открытии сразу же все дела высвечиваются, более-менее удобно».

Ответ 5: «Список дел, назначенных к слушанию найти было очень трудно. Оказывается, они в самом-самом конце. Все ближайшие - это одни кредиторы, о взыскании материальных средств, лично мне неинтересны».

Студенты справились с этим заданием. Некоторым понадобилось больше времени для поиска нужной информации, однако здесь мог сыграть свою роль фактор усталости.

Bonpoc: Допустим, Вы захотели присутствовать на рассмотрении какого-либо дела, подведомственного мировым судьям, на другом судебном участке. Попробуйте на сайте найти мировых судей и дела, которые они ведут. Сколько времени у Вас это заняло?

Ответ 1: «1 минута».

Ответ 2: «3 секунды».

Oтвет 3: «Я нашла, там есть вкладка слева «Суды Санкт-Петербурга», перешла по ней, там список различных судов. Самый последний участок Мирового судьи, я нажала по нему, там есть судебные участки по номерам в СПб. Можно выбрать любой участок, я выбрала и по нему перешла по ссылке, видимо, на сайт этого судебного участка, но этот сайт не существует. Значит, теоретически, наверно, можно найти. Это заняло у меня минуту - 2. По ссылкам судебных участков сайтов, похоже, не существует. Я нажимаю уже третью ссылку и мне Google пишет, что ему не удалось этого сделать. Я попробовала открыть вкладку «Районный суд», «Городской суд», там «Василеостровский районный суд», «Выборгский районный суд» и т.д. по районам Санкт-Петербурга. Там открываются вкладки с каждым районным судом и написан адрес, также телефон приемной, e-mail, официальный сайт и появляется возможность перейти на официальный сайт другого районного суда. К счастью, он работает и выглядит так же, как сайт Фрунзенского районного суда». 
Ответ 4: «Ссылки по судебным участкам не открываются».

Ответ 5: «На сайты мировых судей по ссылке не перейти, ошибка».

Ответ 6: «В разделе «Участок Мирового судьи» можно перейти на их страницы, но вкладка не открывается, перейти по этой ссылке не удается. B Google'е указано: «Не удается получить доступ к сайту»

Ответ 7: «Список судебных участков по СПб еле нашла, но нашла».

Ответ 8: «Через мобильную версию открываются не все ссылки или они просто не "разворачиваются"».

Время, затраченное пользователями на выполнение этой операции, составило от нескольких секунд до минуты. Пользователи, не испытавшие трудностей с выполнением данного задания, вероятно, начали осваиваться со спецификой и структурой сайта и могли просто увидеть расположение кнопки в ходе исследования. Обнаружилась также еще одна важная деталь: неполадки в работе с сайтом - ссылка перемещает пользователей на нефункционирующий сайт.

Bonpoc: Попробуйте заполнить электронное обращение. Сколько времени у Вас на это потребовалось?

Ответ 1: «Я перешла по вкладке «Подача процессуальных документов в электронном виде», но, видимо, это не то, потому что там не совсем просто обращения. Там все очень сложно и надо проходить регистрацию. Видимо, где-то на сайте есть почта и можно написать по ней. Потом мне подсказали, что можно зайти в «Обращения граждан», зашла, в принципе тут можно создать и отправить обращение, это довольно удобно - создать заявку, фамилия, имя, отчество, готовые графы «Тема», «Текст», можно оставить свой номер телефона, довольно удобно».

Ответ 2: «За электронное обращение я приняла «Подачу процессуальных документов в электронном виде», где далее запросили регистрацию, как выяснилось позже, это не то, куда нужно подавать электронное обращение. Пункт «Почтовый адрес» не очень стал понятен, потому что дальше запрашивает e-mail. Почтовый индекс не подходит, значит, получается, почтовый адрес подразумевает адрес проживания, вот это смутило, непонятно совсем».

Ответ 3: «Ничего непонятно. В мобильной версии я не нашла вот этого обращения. Зашла через какой-то раздел и меня направило на какой-то незащищенный сайт».

Ответ 4: «Сложно найти пункт "обращения", нашла только через минуту, с помощью подсказок коллег, думаю, было бы логичнее разместить данный пункт вверху страницы сайта».

С этим заданием практически никто из студентов не справился. Спустя пять минут модератор начал давать подсказки, что, впрочем, тоже не гарантировало результат. Получается, что написать электронное обращение в суд - это навык, которому пользователей необходимо специально обучать. При этом, если принять во внимание и тот факт, что согласно ст. 12 п. 1 Ф3 N 59-Ф3 «О порядке рассмотрения обращений граждан Российской Федерации» от 2 мая 2006 г. обращение, поступившее как в электронной, так и письменной форме, в государственный орган, орган местного самоуправления или должностному лицу в соответствии с их компетенцией, рассматривается в течение 30 дней со дня регистрации письменного обращения [28]. Обращения граждан рассматриваются долго и не всегда корректно. Иными словами, пользователь сначала долго и мучительно пытается понять, как именно ему следует писать электронное обращение, понимая, что ответ ему будет дан нескоро и, возможно, совсем не тот, который он ожидал.

Несколько уточняющих вопросов были заданы о ходе заполнения электронного обращения. Так, например, выяснилось, что большинство пользователей не помнят свой почтовый индекс (большинство опрашиваемых студентов - иногородние), поэтому им оставалось только обращаться к поисковым ресурсам. Рядом с каждым пунктом располагается знак вопроса, однако он не столько выдает справку или предоставляет помощь в заполнении формы, сколько дисциплинирует пользователя, требуя от них точности и внимательности при заполнении заявки. 
Вопрос: Как Вы считаете, в двух словах, помогала ли Вам система справляться с задачей? Если да, то каким именно образом?

Ответ 1: «Система абсолютно не помогала, скорее, даже мешала, препятствовала. Вот эти знаки вопроса меня сбили абсолютно, которые не помогали, а только бесили».

Ответ 2: «Всю информацию приходится искать самой, вычитывать, вглядываться в эти ужасные цвета и искать самой. Если бы я реально обращалась и мне нужно было бы выяснить какую-то важную для меня информацию оттуда, скорей всего, я бы выбесилась, потому что ничего непонятно, все бесит и ничего не помогает».

Ответ 3: «В целом, удобно всё, всё доступно. Но оформление сайта, сам дизайн, он напоминает об интернете 2005 года и вводит в полнейшее уныние. А так удобно, ну, терпимо, да».

Автор неслучайно привел наиболее эмоциональные высказывания пользователей. Ни один студент не остался доволен сайтом. Те студенты, которые указали на помощь системы в поиске информации, одновременно с этим отметили, что намного бо́льшую помощь оказали другие пользователи.

Общий вывод: пользователи остались недовольными сайтом, но для большей точности приведем некоторые расчеты, показывающие степень удовлетворенности сайтом.

\section{3. Количественные результаты исследования}

Первый показатель - индекс относительной депривации RD - показывает на степень расхождения ожидания и восприятия пользователей. До начала и по окончанию работы с сайтом пользователей просили оценить параметры удобства, полезности, простоты и понятности интерфейса, а также приятности и комфорта по 10-балльной шкале. Результаты расчета индекса относительной депривации RD представлены в табл. 1.

Таблица 1. Индекс относительной депривации RD пользователей сайта Фрунзенского районного суда

\begin{tabular}{|l|l|l|l|l|}
\hline \multirow{2}{*}{ Показатели } & \multicolumn{4}{|c|}{ Критерии } \\
\cline { 2 - 5 } & \multicolumn{1}{|c|}{ Удобство } & \multicolumn{1}{|c|}{ Полезность } & $\begin{array}{l}\text { Простота и } \\
\text { понятность } \\
\text { интерфейса }\end{array}$ & $\begin{array}{c}\text { Приятность и } \\
\text { комфорт сайта }\end{array}$ \\
\hline $\begin{array}{l}\text { Ожидания } \\
\text { пользователей }\end{array}$ & 6,761905 & 4,652174 & 5,85 & 3,619048 \\
\hline $\begin{array}{l}\text { Восприятие } \\
\text { пользователей }\end{array}$ & 4,736842 & 5,105263 & 5 & 2,9 \\
\hline $\mathrm{RD}$ & 0,299481 & $-0,097393$ & 0,145299 & 0,198684 \\
\hline \multicolumn{7}{|c|}{ Среднее значение RD: 0,136518} \\
\hline
\end{tabular}

Самый высокий депривационный показатель - удобство сайта, составляющий значение, близкое к 0,3. Неудобство сайта вызывает самые сильные чувства недовольства у пользователей. На втором месте располагается показатель приятности и комфорта от работы с сайтом, составивший значение 0,2 . Работа с сайтом вызывает у пользователей чувство дискомфорта. Показатель простоты и понятности интерфейса оказался достаточно низким $(0,15)$, что, вероятно, говорит о том, что сайт суда содержит большое количество специальной терминологии, которой пользователи-неюристы просто не владеют и потому не ждут простоты и понятности от сайта суда. В то же время показатель полезности составил -0,1. Это говорит о том, что сайт оказался полезнее, чем пользователи полагали изначально. Тем больше возникает вопросов к разработчикам.

Второй показатель - индекс удовлетворенности пользователей CSI - рассчитывался согласно методике Фишбейна-Айзена. Согласно данной методике, показатель, находящийся в диапазоне от 0 до 0,6 говорит о неудовлетворенности клиентов - такие клиенты склонны к критике и поиску недостатков. Диапазон от 0,7 до 0,8 характеризует 
клиентов как «нейтралов», которые в целом остались довольны, но при этом равнодушны, и только значение показателя, находящееся в диапазон от 0,9 до 1,0 указывает на удовлетворенность клиентов, которые будут рекомендовать услуги другим клиентам.

Результаты расчета индекса удовлетворенности пользователей CSI представлены в табл. 2.

Таблица 2. Индекс удовлетворенности пользователей сайта Фрунзенского районного суда

\begin{tabular}{|l|l|l|l|l|}
\hline \multicolumn{1}{|c|}{$\begin{array}{c}\text { Оцениваемый } \\
\text { параметр }\end{array}$} & $\begin{array}{c}\text { Средняя } \\
\text { оценка } \\
\text { важности } \\
\text { параметра (по } \\
\text { 10-ти балльной } \\
\text { шкале) }\end{array}$ & $\begin{array}{c}\text { Вес параметра } \\
\text { в общей оценке } \\
\text { удовлетворен- } \\
\text { ности }\end{array}$ & $\begin{array}{c}\text { Средняя оценка } \\
\text { уровня удовлет- } \\
\text { воренности } \\
\text { параметром (по } \\
\text { 7-ми балльной } \\
\text { шкале) }\end{array}$ & $\begin{array}{c}\text { вдовлетворенно } \\
\text { сти } \\
\text { оценка уровня } \\
\text { Вдовен }\end{array}$ \\
\hline Удобство & 6,761905 & $32,38 \%$ & 4,736842 & 1,5338 \\
\hline Полезность & 4,652174 & $22,28 \%$ & 5,105263 & 1,1375 \\
\hline $\begin{array}{l}\text { Простота и } \\
\text { понятность } \\
\text { интерфейса }\end{array}$ & 5,85 & $28,01 \%$ & 5 & 1,4005 \\
\hline $\begin{array}{l}\text { Приятность и } \\
\text { комфорт }\end{array}$ & 3,619048 & $17,33 \%$ & 2,9 & 0,5026 \\
\hline $\begin{array}{l}\text { Общая взвешенная } \\
\text { оценка уровня } \\
\text { удовлетворенности }\end{array}$ & & & & 4,57437 \\
\hline СSI & & & & $45,7 \%$ \\
\hline
\end{tabular}

Индекс составил 45,7 \%, или 0,46, явно свидетельствующий о неудовлетворенности пользователей. Такое значение указывает на то, что пользователи будут обращаться на сайт суда (и, вероятно, непосредственно в суд) только в случае крайней необходимости. Сайт не создает впечатление проводника в мир осознанного намерения защищать свои права, гарантированные Конституцией, напротив, он отталкивает пользователя нескрываемым намерением соответствовать букве закона, а не нуждам граждан. Результаты данного показателя - это не только суммарные претензии к разработчику, но и большие сомнения в целях стратегии цифрового правосудия.

\section{4. Опрос экспертов}

Эксперты только подтвердили все выводы, сделанные в ходе исследования, также отметив ряд существенных деталей, не выясненных в ходе юзабилити-тестирования. Для экономии времени далее будут представлены наиболее важные достоинства и недостатки сайта, которые отметили эксперты.

Александр Калмыков, тестировщик («Яндекс»):

Минусы:

1. Полностью устаревший дизайн.

2. Кнопка «Развернуть» в карточке справа сверху не нужна. Пользователю не понятно, что за ней скрывается, а электронную почту больше нигде не посмотреть. Для контактов вообще обычно делают отдельную вкладку в меню сайта, здесь многое разбросано по главной странице, что неудобно.

3. У всех пунктов меню есть иконка галочки (иконка дропдауна). Пользователь ожидает, что по клику на это меню раскрывается выпадающий список (дропдаун). Вместо этого его просто бросает на другую страницу. Поэтому их надо либо убрать, либо сделать выпадающий список.

4. Смысл «главного» текста («Уважаемые посетители сайта»), на котором акцентируется внимание пользователя, понятен далеко не с первого раза. Видимо, если он 
вывешен на главную страницу, проблема с подписями, которая в нём описана, часто встречается. А путей её решения нет, только ссылка на официальный документ, в котором незнающий человек запутается.

5. Дублирующаяся информация: левое меню «О суде» - это фактически главная страница. Калькулятор госпошлины и список дел как в верхнем меню, так и в «О суде» $=>$ «Для граждан». Основная проблема сайта: информация слабо структурирована и не понятно, где что искать, а когда еще и дублируется - еще один признак, что организовано плохо, и даже у разработчика не было понимания, где что находится.

6. В мобильной версии меню просто дублируется два раза. Ее в принципе надо делать с нуля, начать хотя бы с того, что добавить обычное боковое меню, постоянно скроллить вверх-вниз неудобно.

Плюс: удобный калькулятор госпошлины, несмотря на его дизайн. Можно сформировать и распечатать квитанцию.

Эксперт оценил сайт на 4 балла из 10.

Антон Гончаров, руководитель фото- и видеостудии «Atlant makes...»:

Минусы:

1. Основные цвета сайта - коричневые, а важные слова на страницах, начиная с главной, выделены ярко-красным. Это вызывает раздражение и дискомфорт.

2. Неудачно подобраны шрифты: использованы стандартное сочетание Times New Roman и Arial, но на одной странице.

3. Однозначно не хватает системы навигации (карты), чтобы пользователь мог найти суд, не вбивая его адрес в «Яндекс. Картах», а сразу нажать ссылку и увидеть местоположение

4. Слабо проработана версия для слабовидящих.

Плюсы:

1. Сайт имеет чёткую структуру.

2. Палитра основных цветов сайта благодаря пастельным оттенкам смотрится грамотно.

3. Нет ничего лишнего, сайт не перегружен, а значит пользователь не отвлекается на посторонние элементы интерфейса.

Эксперт оценил сайт на 5 баллов из 10.

Полина Будянская, web-дизайнер («Fmedia»):

Минусы:

1. В левом верхнем углу лишние и отвлекающие пункты меню. При нажатии на логотип пользователь попадает на главную страницу, это общепринято и понятно. Здесь еще раз продублирована кнопка главной страницы, что отвлекает. Карта сайта опять же дублируется, она есть слева на странице, сбоку. Иконку поиска принято располагать справа, для удобства пользователя.

2. Дропдаун вводит пользователя в заблуждение, что меню будет выпадать списком, а оно просто открывается в новой странице. Ее следует убрать.

3. При нажатии на пункт меню «Подача процессуальных документов в электронном виде» страница должна открываться в новом окне, так как осуществляется переход на другой сайт. Это вводит в заблуждение и сложно понять, как вернуться обратно.

4. Непонятно, зачем вверху справа есть кнопка «Развернуть». Открывается всего лишь одна строка с почтой (см. Рис. 2), чтобы все вместилось легче и логичней растянуть плашку с информацией.

5. Крупно выделено, что есть версия для слабовидящих, но по факту ее нет. Невозможно читать.

6. Цвета и шрифты (подбор цветов, размер шрифтов, логичность использования жирных шрифтов и подчеркивания) оставляют желать лучшего.

Плюсов в разработке данного сайта эксперт не выделил.

Эксперт оценил сайт на 5 баллов из 10. 


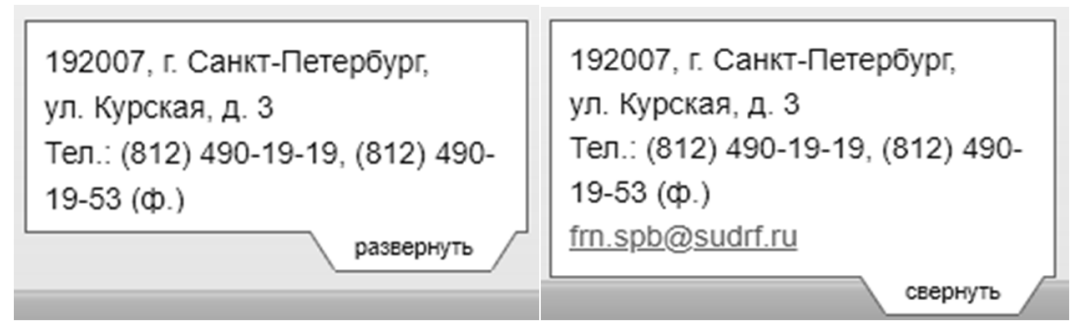

Рис. 2. Результат нажатия кнопки «Развернуть» на главной странице сайта

Среднее арифметическое по экспертным оценкам составляет 4,67, что достаточно близко индексу удовлетворенности пользователей (CSI).

\section{4. Обсуждение}

Результаты этого исследования довольно неутешительные. Поскольку сайты судов РФ сконструированы по единым стандартам и имеют одинаковую структуру и цветовое решение, то не будет преувеличением сделать вывод о том, что не только сайт Фрунзенского районного суда, но и подавляющее большинство сайтов судов представляют собой дорогостоящие и малоэффективные проекты.

Возражения, которые могут возникнуть у исследователей, вероятно, можно разделить на две группы:

1. Методология исследования. С одной стороны, экспертная оценка обычно дает более содержательные результаты, потому работа с рядовыми пользователями может оказаться бесполезной и дублирующей. С другой - уровень относительной депривации применяется, в первую очередь, для анализа политических конфликтов. Наконец, расчет индекса удовлетворенности пользователей по методике Фишбейна-Айзена имеет ряд недостатков, связанных преимущественно с общим характером оценки.

На такие вероятные замечания можно возразить тем, что экспертная оценка обычно более рациональна, чем мнения пользователей. Последние отличаются большей эмоциональностью и сигнализируют о настроениях клиентов, оценивающих интерфейс с точки зрения удовлетворенности/неудовлетворенности. Неудовлетворенность от обманутых ожиданий лежат и в основе методики измерения относительной депривации Т.Р. Гарра. Автор полагает, что эмоциональная оценка сайта в юзабилити-тестинге так же важна, как и его рациональная составляющая (цели, интересы, результаты и пр.). Индекс Фишбейна-Айзена действительно применяется для общей оценки продукта или услуги, но именно общая оценка и была целью данного исследования.

2. Сложность государственного устройства. Государственные сайты представляют собой сложные системы, отражающие сложность самого государственного устройства, и поэтому пользователи, осваивая сайты, осваивают и само государственное устройство. На этом основании замечания, касающиеся трудности восприятия, не вполне уместны. Однако и здесь можно возразить: во-первых, сложность государства слабо связана с дизайном сайтов; во-вторых, пользователи обращаются на сайты обычно для того, чтобы получить какую-либо услугу либо выяснить интересующую их информацию. Получение услуг и информации, как показало исследование, осложнено неудобством самого сайта.

Стоит отметить также и тот факт, что цифровизация органов государственной власти находится в развитии, и те недостатки, на которые мы указали в ходе исследования, будут со временем устранены.

Работа выполнена при финансовой поддержке Российского научного фонда, грант № 1918-00210. Автор искренне благодарит студентов Санкт-Петербургского института психологии и социальной работы за всевозможное содействие в работе над этим исследованием. 


\section{Литература}

[1] Концепция государственной информационной политики Российской Федерации // Институт развития информационного общества. URL: http://www.iis.ru/library/sip/ (дата обращения: 29.01.2019).

[2] О Концепции информационной политики судебной системы: постановление Совета судей РФ от 16.11.2001 № 60. ИПС КонсультантПлюс.

[3] Федеральный закон 22.12.2008 N 262-Ф3 «Об обеспечении доступа к информации о деятельности судов в Российской Федерации». ИПС КонсультантПлюс.

[4] Верховный сайт. Объявлен тендер на обслуживание ГАС «Правосудие» // Официальный сайт газеты «Коммерсантъ». URL: https://www.kommersant.ru/doc/760587 (дата обращения: 29.01.2019).

[5] Бесшабашнов С.В., Денисов А.А. Сайт от идеи до реализации // Интернет-маркетинг. 2006. № 4. C. 238-248.

[6] Kim-Phuong L. Vu, Proctor R.W. (eds). The Handbook of Human Factors in Web Design. Mahwah, New Jersey; London: Lawrence Erlbaum Associates Publ., 2005.

[7] Seffah A., Gulliksen J., Desmarais M.C. Human-Centered Software Engineering - Integrating Usability in the Software Development Lifecycle. Dordrecht: Springer, 2005.

[8] Nielsen J. Usability Engineering. San Francisco: Academic press, 1993.

[9] Krug S. Don't Make Me Think: A Common Sense Approach to Web Usability. Berkeley: New Riders Press, 2005.

[10]Blythe M.A., Overbeeke K., Monk A.F., Wright P.C. Funology: From Usability to Enjoyment. Dordrecht: Kluwer Academic Publishers, 2005.

[11]Dumas J.S., Loring B.A. Moderating Usability Tests Principles and Practices for Interacting. Burlington: Morgan Kaufmann, 2008.

[12]Wroblewski L. Site-Seeing - A Visual Approach to Web Usability. New York: Wiley, 2002.

[13]Koyani S.J., Bailey R.W., Nall J.R. Research-Based Web Design \& Usability Guidelines. Computer Psychology (August 2004).

[14]Fishbein M., Ajzen I. Predicting and Changing Behavior. The Reasoned Action Approach. New York; Hove: Psychology Press, 2015.

[15] Parasuraman A., Zeithaml V., Berry L. SERVQUAL: A Multiple-Item Scale for Measuring Consumer Perceptions of Service Quality // Journal of Retailing. 1988. Vol. 64, № 1. P. 12-40.

[16]Parsasuraman A., Zeithaml V., Berry, L. Reassessment Expectations as a Comparison Standard in Measuring Service Quality: Implications for Further Research // Journal of Marketing.1994. Vol. 5. P. 111-124.

[17]Гарр Т.Р. Почему люди бунтуют. СПб: Питер, 2005.

[18]Аносов А.В. Информационно-правовые вопросы формирования электронного правосудия в Российской Федерации: дисс. на соискание уч. ст. канд. юрид. наук. М., 2016.

[19]Кокотова Е.И. Правовое регулирование применения информационных технологий в судах общей юрисдикции: дисс. на соискание уч. ст. канд. юрид. наук. М., 2009.

[20]Чижов М.В. Применение информационных и коммуникационных технологий в судебной деятельности в условиях формирования информационного общества: дисс. на соискание уч. ст. канд. юрид. наук. М., 2013.

[21]Павлов И.Ю., Голубева Е.Г., Голубев В.О. Методика мониторинга официальных сайтов органов власти // Фонд свободы информации. СПб., 2011. URL: http://infometer.org/monitoring/metodika/vvedenie (дата обращения: 21.04.2019)

[22]Официальный сайт проектного центра "Информетр". URL: https://read.infometer.org (дата обращения: 21.04.2019).

[23]Рейтинг открытости судебной системы. $2017 . \quad$ URL: http://system.infometer.org/ru/monitoring/467/rating/?name= (дата обращения: 21.04.2019 г.). 
[24]Завескин М.В. Анализ системы информационного управления в социальноэкономической сфере муниципального образования г. Каменск-Уральский // Human $\begin{array}{llllll}\text { progress. } & 2017 . & \text { T. } & 3 \text {, № } & 5 . & \text { URL: }\end{array}$ human.com/images/2017/tom3_5/Zaveskin.pdf (дата обращения: 21.04.2019 г.).

[25]Страшко И.О. Специфика создания сайта для органов государственной власти // Вестник магистратуры. 2014. № 1(28). С. 144-147.

[26]Меньшикова Г.А., Евстратчик С.В. Сайты государственных организаций: оценка степени соответствия требованиям закона и нуждам пользователей // Стратегические коммуникации в бизнесе и политике. 2018. № 4. С. 179-185.

[27]Официальный сайт АНО «Независимый Исследовательский Центр». Отношение россиян к судебной системе (итоги всероссийского опроса). URL: http://исследовательский-центр.pф/otnoshenie-rossiyan-k-sudebnoj-sisteme-itogivserossijskogo-oprosa/?ckattempt=1 (дата обращения: 17.04.2019 г.).

[28]Федеральный закон от 2 мая 2006 г. N 59-Ф3 «О порядке рассмотрения обращений граждан Российской Федерации». ИПС КонсультантПлюс.

\title{
Methodology for Assessing Users' Satisfaction with the Websites of the General Jurisdiction Courts: Case of St. Petersburg Frunzensky District Court Website
}

\author{
Konstantin S. Kondratenko
}

\section{St. Petersburg State University}

The article touches upon the problem of users' satisfaction with the state websites of the Russian Federation, in particular, the websites of General jurisdiction courts, and that is quite relevant today. As an example, the site of the Frunze district court was chosen, because the sites of the courts are popular state sites among the citizens (the site of the Frunze district court was chosen randomly). The research is based on the well-known methods of conducting such studies as usability testing and expert survey. The General principles of web ergonomics describing the model of human-computer interaction from the point of view of heuristic approach to software were chosen as the key analytical parameters. The study also analyzes differences in user expectations and perceptions and calculates a user satisfaction index (CSI). The article can be useful for website developers, web designers, testers, moderators of usability studies, specialists in the fields of digital public governance, law, political science, as well as all those interested in this issue.

Keywords: usability, usability testing, state websites, user satisfaction index, user satisfaction

Reference for citation: Kondratenko K.S. Methodology for Assessing Users' Satisfaction with the Websites of the General Jurisdiction Courts: Case of St. Petersburg Frunzensky District Court Website // The State and Citizens in the Electronic Environment. Vol. 3 (Proceedings of the XXII International Joint Scientific Conference «Internet and Modern Society», IMS-2019,

St. Petersburg, June 19-22, 2019). - St. Petersburg: ITMO University, 2019. P. 48 - 65. DOI: 10.17586/2541-979X-2019-3-48-65

\section{Reference}

[1] Koncepciya gosudarstvennoj informacionnoj politiki Rossijskoj Federacii // Institut razvitiya informacionnogo obshchestva. URL: http://www.iis.ru/library/sip/ (access date: 29.01.2019). (In Russian) 
[2] O Koncepcii informacionnoj politiki sudebnoj sistemy: postanovlenie Soveta sudej RF ot 16.11.2001 № 60. IPS Konsul'tantPlyus.

[3] Federal'nyj zakon 22.12.2008 N 262-FZ «Ob obespechenii dostupa k informacii o deyatel'nosti sudov v Rossijskoj Federacii». IPS Konsul'tantPlyus.

[4] Verhovnyj sajt. Ob"yavlen tender na obsluzhivanie GAS "Pravosudie" // Oficial'nyj sajt gazety "Kommersant". URL: https://www.kommersant.ru/doc/760587 (access date: 29.01.2019). (In Russian)

[5] Besshabashnov S.V., Denisov A.A. Sajt ot idei do realizacii // Internet-marketing. 2006. № 4. S. 238-248.

[6] Kim-Phuong L. Vu, Robert W. Proctor (editors). The Handbook of Human Factors in Web Design. Mahwah, New Jersey; London: Lawrence Erlbaum Associates Publ., 2005.

[7] Seffah A., Gulliksen J., Desmarais M.C. Human-Centered Software Engineering - Integrating Usability in the Software Development Lifecycle. Dordrecht: Springer, 2005.

[8] Nielsen J. Usability Engineering. San Francisco: Academic press, 1993.

[9] Krug S. Don't Make Me Think: A Common Sense Approach to Web Usability. Berkeley: New Riders Press, 2005.

[10]Blythe M.A., Overbeeke K., Monk A.F., Wright P.C. Funology: From Usability to Enjoyment. Dordrecht: Kluwer Academic Publishers, 2005.

[11]Dumas J.S., Loring B.A. Moderating Usability Tests Principles and Practices for Interacting. Burlington: Morgan Kaufmann, 2008.

[12]Wroblewski L. Site-Seeing - A Visual Approach to Web Usability. New York: Wiley, 2002.

[13]Koyani S.J., Bailey R.W., Nall J.R. Research-Based Web Design \& Usability Guidelines. Computer Psychology (August 2004).

[14]Fishbein M., Ajzen I. Predicting and Changing Behavior. The Reasoned Action Approach. New York; Hove: Psychology Press, 2015.

[15]Parasuraman A., Zeithaml V., Berry L. SERVQUAL: A Multiple-Item Scale for Measuring Consumer Perceptions of Service Quality. Journal of Retailing, Vol. 64. No. 1. (1988). P. 1240.

[16]Parsasuraman A., Zeithaml V., Berry, L. Reassessment Expectations as a Comparison Standard in Measuring Service Quality: Implications for Further Research. Journal of Marketing, Vol. 5. January (1994). P. 111-124.

[17]Garr T.R. Pochemu lyudi buntuyut. SPb.: Piter, 2005.

[18]Anosov A.V. Informacionno-pravovye voprosy formirovaniya elektronnogo pravosudiya $\mathrm{V}$ Rossijskoj Federacii: diss. na soiskanie uch. st. kand. yurid. nauk. M., 2016.

[19]Kokotova E.I. Pravovoe regulirovanie primeneniya informacionnyh tekhnologij v sudah obshchej yurisdikcii: diss. na soiskanie uch. st. kand. yurid. nauk. M., 2009.

[20]CHizhov M.V. Primenenie informacionnyh i kommunikacionnyh tekhnologij v sudebnoj deyatel'nosti v usloviyah formirovaniya informacionnogo obshchestva: diss. na soiskanie uch. st. kand. yurid. nauk. M., 2013.

[21]Pavlov I.YU., Golubeva E.G., Golubev V.O. Metodika monitoringa oficial'nyh sajtov organov vlasti // Fond svobody informacii. SPb., 2011. URL: http://infometer.org/monitoring/metodika/vvedenie (access date: 21.10.2015). (In Russian)

[22]Oficial'nyj sajt proektnogo centra "Informetr". URL: https://read.infometer.org (access date: 21.04.2019). (In Russian)

[23]Rejting otkrytosti sudebnoj sistemy. $2017 . \quad$ URL: $\mathrm{http}: / /$ system.infometer.org/ru/monitoring/467/rating/?name= (access date: 21.04.2019). (In Russian)

[24]Zaveskin M.V. Analiz sistemy informacionnogo upravleniya v social'no-ekonomicheskoj sfere municipal'nogo obrazovaniya g. Kamensk-Ural'skij // Human progress. 2017. T. 3. № 5. URL: http://progress-human.com/images/2017/tom3_5/Zaveskin.pdf (access date: 21.04.2019). (In Russian) 
[25]Strashko I.O. Specifika sozdaniya sajta dlya organov gosudarstvennoj vlasti // Vestnik magistratury. 2014. № 1(28). S. 144-147.

[26]Men'shikova G.A., Evstratchik S.V. Sajty gosudarstvennyh organizacij: ocenka stepeni sootvetstviya trebovaniyam zakona i nuzhdam pol'zovatelej // Strategicheskie kommunikacii v biznese i politike. 2018. № 4. S. 179-185.

[27]Oficial'nyj sajt ANO «Nezavisimyj Issledovatel'skij Centr». Otnoshenie rossiyan k sudebnoj sisteme (itogi vserossijskogo oprosa). URL: http://исследовательский-центр.pф/otnoshenierossiyan-k-sudebnoj-sisteme-itogi-vserossijskogo-oprosa/?ckattempt $=1$ (access date: 17.04.2019). (In Russian)

[28]Federal'nyj zakon ot 2 maya 2006 g. N 59-FZ «O poryadke rassmotreniya obrashchenij grazhdan Rossijskoj Federacii»». IPS Konsul'tantPlyus. 